\title{
TECNOLOGIA DE APLICAÇÃO EMPREGADA NO CONTROLE DO PERCEVEJO- DE-RENDA EM SERINGUEIRA
}

\author{
Lilian Lúcia $\operatorname{Costa}^{1}$, Gustavo de Nóbrega Romani ${ }^{1}$, Marcelo da Costa Ferreira ${ }^{1}$. \\ ${ }^{1}$ Universidade Estadual Paulista (UNESP). Via de Acesso Prof. Paulo Donato Castellane, s/n. Jaboticabal, SP. CEP. 14.884- \\ 900,e-mail do autor correspondente: lilianlcosta@yahoo.com.br
}

\section{RESUMO}

O método utilizado para o controle do percevejo-de-renda é o químico, entretanto, poucos avanços têm ocorrido na área de tecnologia de aplicação com a heveicultura que avaliam fatores relacionados à eficácia de produtos e dosagens. Desta forma, o objetivo deste experimento foi avaliar a translocação do produto tiametoxan, aplicado na parte baixa das plantas e no solo, em três dosagens, e observar o tratamento fitossanitário que proporciona melhor controle do percevejo-de-renda. O experimento foi conduzido na fazenda Plantações E. Michelin Ltda. localizada no município de Itiquira, MT. As variáveis analisadas foram modos de aplicação: granulados no solo, granulados dissolvidos aplicados no solo, pulverizados no tronco e granulados dissolvidos aplicados no painel e diferentes dosagens: $0,5 \mathrm{~g}, 0,75 \mathrm{~g}$ e $1,0 \mathrm{~g}$ de ingrediente ativo por planta de seringueira. A aplicação de granulado via solo na dosagem de 1,0 g i.a/planta foi o tratamento que proporcionou a melhor eficiência de controle da ninfa do percevejo-de-renda. Para o controle de adultos de $L$. heveae verifica-se que os tratamentos que apresentaram melhor eficiência de controle foram granulado via solo nas dosagens de 0,75 e 1,0 g i.a/planta e aplicação através do pincelamento de caule nas dosagens de 0,50 e $0,75 \mathrm{~g}$ i.a/planta, sendo que o tratamento através do pincelamento na dosagem de $0,5 \mathrm{~g}$ i.a/planta apresentou maior freqüência de melhor tratamento no decorrer das avaliações para o controle de adultos do percevejo-de-renda. $\mathrm{O}$ modo de aplicação granulado no solo e o pincelamento são os tratamentos mais indicados para o controle de $L$. heveae por apresentar eficiência tanto para o adulto como para a ninfa.

Palavras-chave: controle químico, Leptopharsa heveae, método de aplicação

\section{TECHNOLOGY OF APPLICATION USED IN THE CONTROL OF THE RUBBER TREE LACEBUG}

\begin{abstract}
The method used to control rubber tree lacebug is the chemical one, however little progress has occurred in the area of technology application with the rubber tree that assess factors related to the effectiveness of products and dosages. Thus, the objective of this experiment was to evaluate the translocation of tiamethoxan applied at the bottom of the plants and of soil in three dosages, and observe which one would provide better control of the rubber tree lacebug. The experiment was conducted in the plantations of E. Michelin Ltd. located in Itiquira, State of Mato Grosso, Brazil. The variables were: (1)modes of application: granular in soil, dissolved granules on soil, sprayed on the trunk and pellets dissolved on the panel and (2) applying of
\end{abstract}


different doses: $0.5 \mathrm{~g}, 0.75 \mathrm{~g}$ and $1.0 \mathrm{~g}$ of active ingredient per rubber plant. The application of granules in the soil at a dosage of $1.0 \mathrm{~g}$ ai / plant was the treatment providing the most efficient control of lacebug nymphs. For the control of $\mathrm{t} L$. heveae adults the best treatments were granulated in the soil at doses of 0.75 and $1.0 \mathrm{~g}$ ai / plant and brushing application on panel at doses of 0.50 and $0.75 \mathrm{~g}$ ai / plant. The treatment by brushing at a dosage of $0.5 \mathrm{~g}$ ai / plant had the highest frequency of better one during evaluations of lacebug adults. The mode of application of granular on soil and brushing panel are the most suitable treatments for the control of $L$. heveae adults and nymphs.

Key words: chemical control, Leptopharsa heveae, method of application

\section{INTRODUÇÃO}

A seringueira, Hevea brasiliensis, da qual é extraída a borracha natural, vem se expandindo de forma considerável, desde 1970, nos Estados do Mato Grosso, São Paulo e Bahia (Bernardes, 1992), e a sua industrialização se constitui num segmento importante da economia agroindustrial do Brasil (Pino et al. 2000).

Nas grandes áreas propícias ao cultivo da seringueira em sistema de monocultura verifica-se a adaptação de pragas e doença que causam sérios problemas de interferência na fisiologia e consequente redução da produtividade das plantas (Scomparim 1997). Entre os insetos pragas que têm causado danos à cultura, destaca-se o percevejo-de-renda, Leptopharsa heveae Drake \& Poor (Hemiptera: Tingidae) considerado a praga mais prejudicial dos seringais (Batista Filho et al. 1995, 1998).

Tanto o adulto quanto a ninfa sugam a seiva das plantas, diminuem sua atividade fotossintética, debilitando-as (Vendramim 1992). Como consequência, promove a desfolha fora de época, provocando, assim, o surgimento de brotações precoces que favorecem a infecção do fungo Microcyclus ulei (P. Henn.) v. Arx., agente causal do mal-das-folhas (Val 1994), mesmo em áreas de escape (Junqueira 1994).

Em altas infestações o inseto provoca redução de $28 \%$ no crescimento em altura e de $44,5 \%$ no diâmetro do colo das plantas, em mudas, e queda na produção de látex em até 30\% (Tanzini \& Lara 1998). Dessa forma, fazem-se necessários tratamentos fitossanitários para diminuição das perdas devido à ocorrência deste inseto.

O método de controle comumente utilizado é o químico, que consiste na aplicação de inseticidas direta ou indiretamente sobre $\mathrm{o}$ inseto, em concentrações adequadas, causando morte do mesmo (Junqueira et al. 1999). Entretanto, devido ao uso de produtos fitossanitários em grandes quantidades e o alto investimento na produção agrícola há necessidade de aplicações mais precisas e eficientes por razões de ordem ambiental e econômica (Carpenter et al. 1983; Matthews 2000).

Apesar dos inúmeros produtos disponibilizados pela indústria química e do crescimento da área utilizada por culturas, poucos avanços tm ocorrido na área de tecnologia de aplicação, sendo a pulverização de culturas arbóreas, ainda de padrão muito baixo e desperdiçador (Wiles 1996).

São poucos os trabalhos com a heveicultura que avaliam fatores relacionados à eficácia de produtos $\mathrm{e}$ dosagens em função da tecnologia de aplicação. Como alguns produtos para controle do percevejo-de-renda são sistêmicos, é provável que a necessidade de cobertura possa ser menor ou mesmo que o sistema de aplicação seja alterado para 
outras práticas, como na aplicação de solo. Desta forma, o objetivo deste experimento foi avaliar a translocação do produto tiametoxan, aplicado na parte baixa das plantas e no solo, em três dosagens, e observar qual o tratamento fitossanitário que proporciona melhor controle do percevejode-renda.

\section{MATERIAL E MÉTODOS}

O experimento foi conduzido na fazenda Plantações E. Michelin Ltda. (PEM) localizada no município de Itiquira, MT, no período de 03/11/2004 a 04/03/2005. Foram utilizadas árvores de seringueira do clone GT1 situado na parcela $211 \mathrm{C}$ da PEM, que não recebe pulverizações, portanto sujeitas a infestação natural do percevejo-de-renda. $\mathrm{O}$ delineamento experimental utilizado foi em blocos casualizados e quatro repetições.
Utilizaram-se cinco linhas com setenta e oito plantas cada. A primeira, a terceira e a quinta linhas não receberam aplicação dos produtos, sendo destinadas a bordadura das parcelas experimentais. A segunda e a quarta linhas foram divididas em quatro blocos (A, B, C e D), sendo os blocos A e B colocados na segunda e C e D, na quarta linha.

Cada bloco foi composto por trinta e nove plantas divididas em treze tratamentos de três plantas compondo as parcelas experimentais. Em cada parcela experimental somente a planta central foi avaliada servindo as demais de bordadura.

As variáveis analisadas foram modos de aplicação: granulados no solo, granulados dissolvidos aplicados no solo, pulverizados no tronco e granulados dissolvidos aplicados no painel, todos nas seguintes dosagens: 0,5 $\mathrm{g} ; 0,75 \mathrm{~g}$ e $1,0 \mathrm{~g}$ de ingrediente ativo por planta de seringueira (Tabela 1).

Tabela 1. Modos de aplicação e dosagem do tiametoxan aplicado no experimento para controle do percevejo-de-renda. Itiquira - MT, novembro de 2003.

\begin{tabular}{lccc}
\hline Modos de Aplicação & Dosagens (g i.a/planta de seringueira) \\
\hline Granulado (10GR) & 0,50 & 0,75 & 1,00 \\
Regador (250 WG) & 0,50 & 0,75 & 1,00 \\
Pulverizador (250 WG) & 0,50 & 0,75 & 1,00 \\
Pincelamento (250 WG) & 0,50 & 0,75 & 1,00 \\
\hline
\end{tabular}

Antes da aplicação foi realizada uma avaliação prévia na área experimental, com o objetivo de se constatar a presença de ninfas e adultos do percevejo-de-renda por árvore, e os níveis de infestação em cada parcela.

$\mathrm{O}$ produto utilizado neste experimento foi o inseticida sistêmico do grupo dos neocotinóides com tiametoxam sendo o ingrediente ativo, em duas formulações diferentes GR (granulado sólido), aplicado via solo e WG (granulado solúvel em água) aplicado via solo, caule ou folhas, utilizando um regador de jardim, pincel e um pulverizador costal manual para realizar as aplicações.
Os produtos foram pesados em balança analítica do Laboratório de Análise Cromatográfica da P.E.M., sendo levados em alíquotas separadas para cada parcela experimental.

O produto na formulação granulada (10 GR) foi aplicado via solo (10 g.i.a./kg do produto comercial), e distribuído em um sulco contínuo de $5 \mathrm{~cm}$ de profundidade a 50 $\mathrm{cm}$ do tronco, com um comprimento de $6 \mathrm{~m}$ percorrendo desde o centro da primeira planta da parcela até o meio da terceira, em apenas um dos lados das árvores (Figura 1). Foram utilizadas três quantidades do produto comercial 10 GR, para cada dosagem, 100; 
150 e $200 \mathrm{~g}$, perfazendo os três primeiros tratamentos.

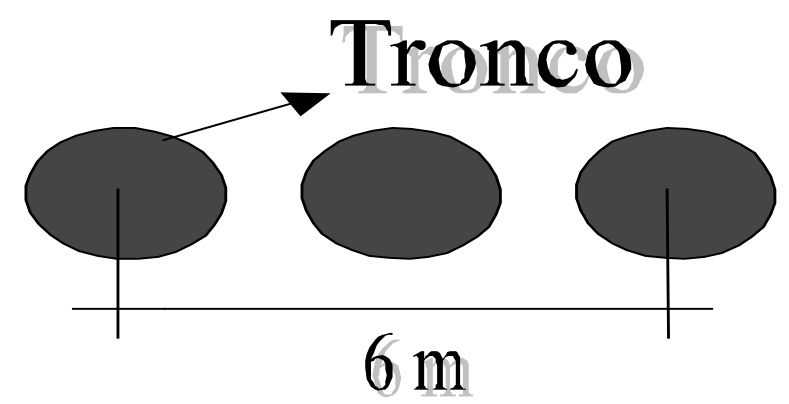

Figura 1. Esquema do posicionamento do sulco para distribuição do granulado em relação às plantas de seringueira.

Com a formulação grânulo dispersível em água $(250 \mathrm{WG})$ foram realizados nove tratamentos, sendo que nos três primeiros foi preparada uma calda com vinte litros de água que foi aplicada com regador de jardim diretamente em solo descoberto, retirando-se a cobertura de palha, numa faixa de nove metros, abrangendo desde um metro e meio antes da primeira árvore da parcela até um metro e meio depois da terceira árvore, aplicando-se meio litro de calda por planta (Figura 2), perfazendo o quarto, quinto e sexto tratamento, sendo utilizadas as seguintes dosagens: $20 \mathrm{~g}$ em $20 \mathrm{~L}$ (0,5 g.i.a./0,5 L/planta); $30 \quad \mathrm{~g}$ em $20 \mathrm{~L} \quad(0,75$ g.i.a./0,5L/planta) e $40 \mathrm{~g}$ em $20 \mathrm{~L}$ sendo 1,0 g.i.a./0,5 L/planta.

Para os três tratamentos seguintes aplicou-se a calda com pulverizador costal manual no colo das plantas na parte inferior do tronco entre o solo e o painel oposto, que foi sangrado em outros anos e não estava sendo utilizado no ano corrente (Figura 3).

Utilizou-se um bico com indução de ar modelo ADIA-MAGNO-4503 (ângulo do jato de $45^{\circ}$ e vazão de $\left.0,3 \mathrm{gal} / \mathrm{min}\right)$. O pulverizador foi calibrado com água, até atingir uma constância de $25 \mathrm{~mL}$ por planta. Foram utilizadas as seguintes dosagens: 0,5 g.i.a./0,025 L/planta; 0,75 g.i.a./0,025 L/planta; e 1,0 g.i.a./0,025 L/planta. , perfazendo os tratamentos 7,8 e 9 .

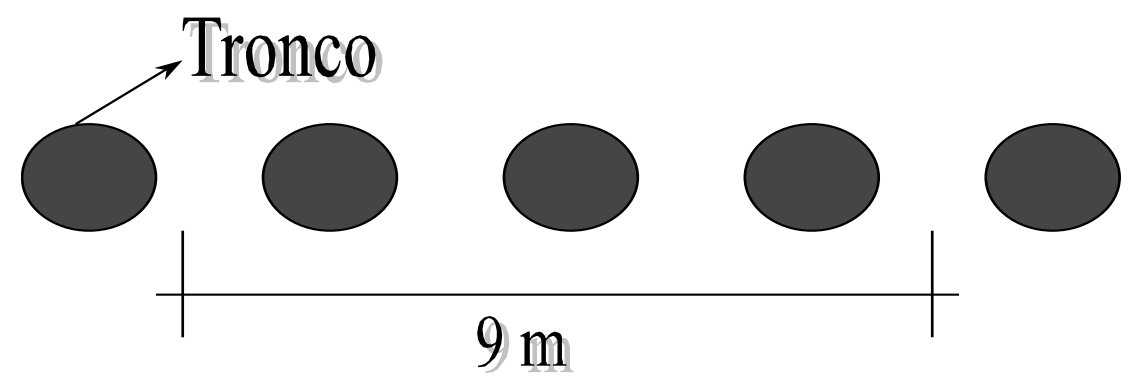

Figura 2. Esquema do posicionamento do sulco para distribuição da calda com aplicador tipo regador. 


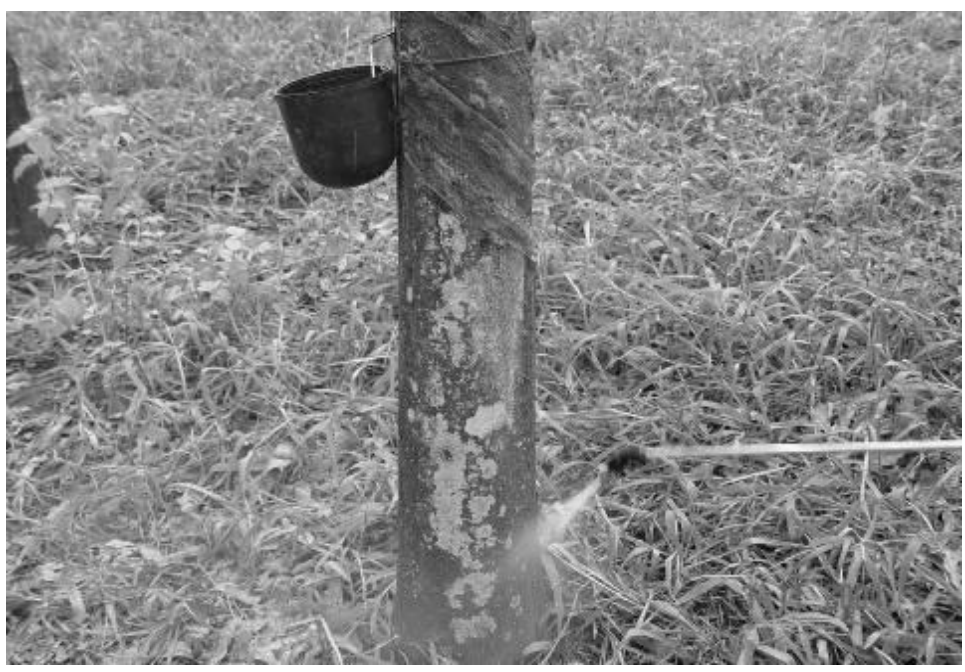

Figura 3. Detalhe da aplicação do tiametoxan no colo da plantas de seringueira, com pulverizador costal manual.

Nos últimos três tratamentos macerou-se o tiametoxam em almofariz com $4 \mathrm{~mL}$ de água. O produto foi aplicado com um pincel tigre de meia polegada no painel oposto da planta, utilizando toda a quantia preparada (Figura 4). Foram utilizadas as seguintes dosagens: 2 g i.a./planta; $3 \mathrm{~g}$ i.a./planta; e 4 g i.a./planta, perfazendo os tratamentos 10,11 e 12 . No tratamento 13 não foi aplicado nenhum produto (tratamento testemunha).

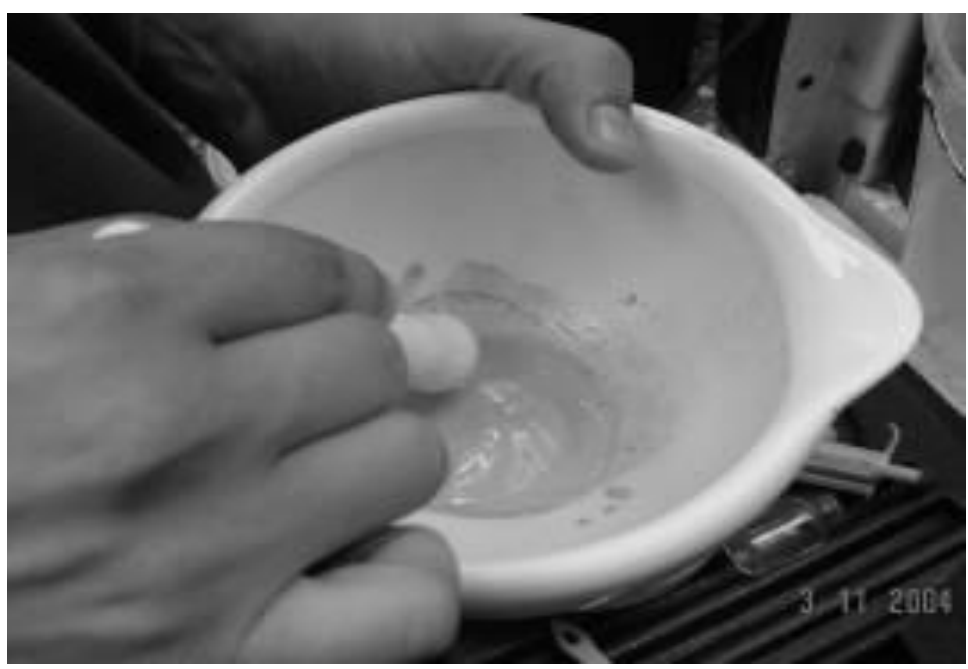

Figura 4. Aspecto da preparação da pasta de aplicação em pincelamento.

Posteriormente, avaliaram-se todas as árvores que receberam os tratamentos e a testemunha, observando em cada árvore, 30 pontos amostrais e contando-se o número de percevejos adultos e ninfas. As avaliações foram realizadas aos 5, 10, 20, 30, 60, $80 \mathrm{e}$ 100, dias após a aplicação.
O número de percevejos (adultos e ninfas) foi somado em cada tratamento (30 pontos amostrais por árvore) para cada data de amostragem e realizado, posteriormente, o cálculo de porcentagem de eficiência utilizando a fórmula de Henderson \& Tilton, apresentada a seguir. O modelo utiliza os 
dados da testemunha para conversão do número de indivíduos em valores de eficiência. Desta forma, a testemunha deixa de figurar nos resultados, não sendo possível, portanto, a sua utilização nas análises estatísticas.

$$
\% E=\left[1-\left(\frac{I d x T p}{I p x T d}\right)\right] x 100, \text { onde: }
$$

$\% E=$ porcentagem de eficiência de controle

$I d=$ Insetos depois

$T p=$ Testemunhas da Prévia

$I p=$ Insetos da prévia

$T d=$ Testemunhas depois

Foi avaliada também a freqüência de ocorrência de cada tratamento nas avaliações fornecendo indiretamente informações dos melhores tratamentos.

\section{RESULTADOS E DISCUSSÃO}

Observa-se no presente estudo que a aplicação de granulado via solo na dosagem de $1,0 \mathrm{~g}$ i.a/planta foi o tratamento que proporcionou a melhor eficiência de controle da ninfa do percevejo-de-renda, com $62 \%$ de eficiência já nos primeiros 5 dias após a aplicação (DAA) do inseticida tiametoxam, atingindo $100 \%$ de eficiência aos 30 e 60 DAA (Tabela 2).

Tabela 2. Porcentagem de eficiência de modos de aplicação e dosagens do produto tiametoxan aplicado no experimento para controle de ninfas do percevejo-de-renda. Itiquira - MT, novembro de 2003.

\begin{tabular}{ccccccccc}
\hline & & \multicolumn{10}{c}{ DAA* } \\
\cline { 3 - 9 } Modos de aplicação & $\begin{array}{c}\text { Dosagens } \\
\text { (g i.a/planta) }\end{array}$ & 5 & 10 & 20 & 30 & 60 & 80 & 100 \\
\hline Granulado & 0,50 & 39 & 27 & 0 & 0 & 100 & 0 & 0 \\
Granulado & 0,75 & 0 & 0 & 0 & 0 & 52 & 0 & 16 \\
Granulado & 1,00 & 62 & 63 & 67 & 100 & 100 & 80 & 65 \\
Regador & 0,50 & 20 & 0 & 0 & 0 & 0 & 41 & 11 \\
Regador & 0,75 & 14 & 0 & 42 & 100 & 100 & 10 & 13 \\
Regador & 1,00 & 0 & 0 & 0 & 0 & 83 & 0 & 0 \\
Pulverizador & 0,50 & 14 & 0 & 0 & 0 & 0 & 5 & 35 \\
Pulverizador & 0,75 & 24 & 0 & 0 & 0 & 100 & 0 & 0 \\
Pulverizador & 1,00 & 0 & 0 & 0 & 0 & 26 & 10 & 2 \\
Pincelamento & 0,50 & 17 & 21 & 0 & 70 & 100 & 0 & 51 \\
Pincelamento & 0,75 & 0 & 0 & 0 & 0 & 0 & 0 & 51 \\
Pincelamento & 1,00 & 4 & 0 & 3 & 100 & 0 & 0 & 20 \\
\hline
\end{tabular}

DAA* Dias após a aplicação 
Outros métodos de aplicação como regador na dosagem de $0,75 \mathrm{~g}$ i.a/planta e pincelamento de caule na dosagem de $0,5 \mathrm{~g}$ i.a./planta também apresentaram boa opção de controle de ninfas do percevejo em relação aos demais tratamentos (Tabela 2), sendo isto comprovado pela frequência com que estes tratamentos apresentaram-se melhores em eficiência de controle das ninfas do percevejo-de-renda (Tabela 3 ).

Tabela 3. Freqüência de ocorrência dos melhores tratamentos após a aplicação do produto tiametoxan para controle de ninfas e adultos do percevejo-de-renda. Itiquira - MT, novembro de 2003.

\begin{tabular}{cccccccc}
\hline & \multicolumn{3}{c}{ Ninfas } & \multicolumn{3}{c}{ Adultos } \\
\cline { 2 - 7 } $\begin{array}{c}\text { Modo de } \\
\text { aplicação }\end{array}$ & $\begin{array}{c}\text { Dosagens } \\
\text { (g i.a/planta) }\end{array}$ & Freq. 1 & Freq. 2 & Freq. & Freq. 1 & Freq. 2 & Freq. \\
\hline Granulado & 0,50 & 1 & 2 & 3 & 0 & 0 & 0 \\
Granulado & 0,75 & 0 & 0 & 0 & 3 & 0 & 3 \\
Granulado & 1,00 & 7 & -- & 7 & 0 & 1 & 1 \\
Regador & 0,50 & 0 & 1 & 1 & 0 & 1 & 1 \\
Regador & 0,75 & 2 & 1 & 3 & 0 & 0 & 0 \\
Regador & 1,00 & 0 & 1 & 1 & 0 & 0 & 0 \\
Pulverizador & 0,50 & 0 & 0 & 0 & 0 & 1 & 1 \\
Pulverizador & 0,75 & 0 & 0 & 0 & 0 & 0 & 0 \\
Pulverizador & 1,00 & 0 & 0 & 0 & 0 & 1 & 1 \\
Pincelamento & 0,50 & 1 & 2 & 3 & 4 & 1 & 5 \\
Pincelamento & 0,75 & 0 & 0 & 0 & 1 & 1 & 2 \\
Pincelamento & 1,00 & 1 & 0 & 1 & 0 & 0 & 0 \\
\hline
\end{tabular}

Freq. 1 = Frequência 1 - Tratamento que apresentou mais vezes maior eficiência no controle de ninfas e adultos do percevejo-de-renda; Freq. 2 = Frequência 2 - Corresponde ao segundo melhor tratamento no controle do percevejo de renda, Freq. $=$ Frequência - Corresponde ao somatório de Frequência 1 e Frequência 2.

Cabe ressaltar que o tratamento granulado de solo (1,0 g i.a/planta) apesar de proporcionar melhor eficiência no controle de ninfas do percevejo-de-renda, o uso de maiores dosagens pode trazer alguns problemas, como resistência da praga ao produto utilizado e maior contaminação ambiental.

Para o controle de adultos de $L$. heveae verifica-se que os tratamentos que apresentaram melhor eficiência de controle foram granulado via solo nas dosagens de 0,75 e 1,0 g i.a/planta e aplicação através do pincelamento de caule nas dosagens de 0,50 e $0,75 \mathrm{~g}$ i.a/planta (Tabela 4), sendo que o tratamento através do pincelamento na dosagem de $0,5 \mathrm{~g}$ i.a/planta apresentou maior frequiência de melhor tratamento no decorrer das avaliações para o controle de adultos do percevejo-de-renda (Tabela 3).

A eficiência observada nos tratamentos em que se utilizaram dosagens menores do inseticida tiametoxam pode ser explicado, pois, as doses recomendadas pelos fabricantes de produtos fitossanitários são estabelecidas em quantidades maiores, 
de tal forma, que assegure o controle do alvo (Devlin et al. 1991). Desta forma, em condições ambientais favoráveis, a dosagem do produto pode ser reduzida e, ainda assim, apresentar controle satisfatório.

Tabela 4. Porcentagem de eficiência de modos de aplicação e dosagens do produto tiametoxan aplicado no experimento para controle de adultos do percevejo-de-renda. Itiquira MT, novembro de 2003.

\begin{tabular}{ccccccccc}
\hline & & \multicolumn{10}{c}{ DAA* } \\
\cline { 3 - 9 } Modos de aplicação & $\begin{array}{c}\text { Dosagens } \\
\text { (g i.a/planta) }\end{array}$ & 5 & 10 & 20 & 30 & 60 & 80 & 100 \\
\hline Granulado & 0,50 & 0 & 0 & 0 & 16 & 0 & 0 & 0 \\
Granulado & 0,75 & 74 & 79 & 51 & 62 & 0 & 39 & 100 \\
Granulado & 1,00 & 65 & 73 & 51 & 72 & 0 & 0 & 28 \\
Regador & 0,50 & 12 & 58 & 20 & 80 & 0 & 0 & 0 \\
Regador & 0,75 & 0 & 0 & 3 & 31 & 0 & 0 & 0 \\
Regador & 1,00 & 6 & 9 & 29 & 76 & 0 & 0 & 0 \\
Pulverizador & 0,50 & 35 & 55 & 36 & 44 & 49 & 0 & 0 \\
Pulverizador & 0,75 & 0 & 32 & 0 & 58 & 0 & 0 & 0 \\
Pulverizador & 1,00 & 21 & 64 & 63 & 69 & 0 & 0 & 0 \\
Pincelamento & 0,50 & 52 & 81 & 65 & 83 & 79 & 0 & 100 \\
Pincelamento & 0,75 & 30 & 61 & 68 & 53 & 0 & 0 & 62 \\
Pincelamento & 1,00 & 27 & 7 & 55 & 49 & 0 & 0 & 35 \\
\hline DAA* Dias após a aplicação & & & & & & & & 0
\end{tabular}

As aplicações realizadas com $\mathbf{o}$ regador e pulverizador não são recomendadas para controle tanto de ninfas como de adultos do percevejo-de-renda devido a menor freqüência de ocorrência destes tratamentos com melhores eficiência de controle da praga (Tabela 3).

Quanto ao período de controle proporcionado pelos melhores tratamentos no controle de ninfas de $L$. heveae verifica- se que todos os tratamentos apresentaram máxima eficiência aos 60 DAA (Figura 5). Entretanto, somente no tratamento granulado na dosagem de $1,0 \mathrm{~g}$ i.a/planta verificou-se uma maior constância na eficiência de controle da praga, ao longo das observações (Figura 5). Para o controle do adulto, os melhores tratamentos acompanharam a dinâmica populacional da praga (Figura 6). 


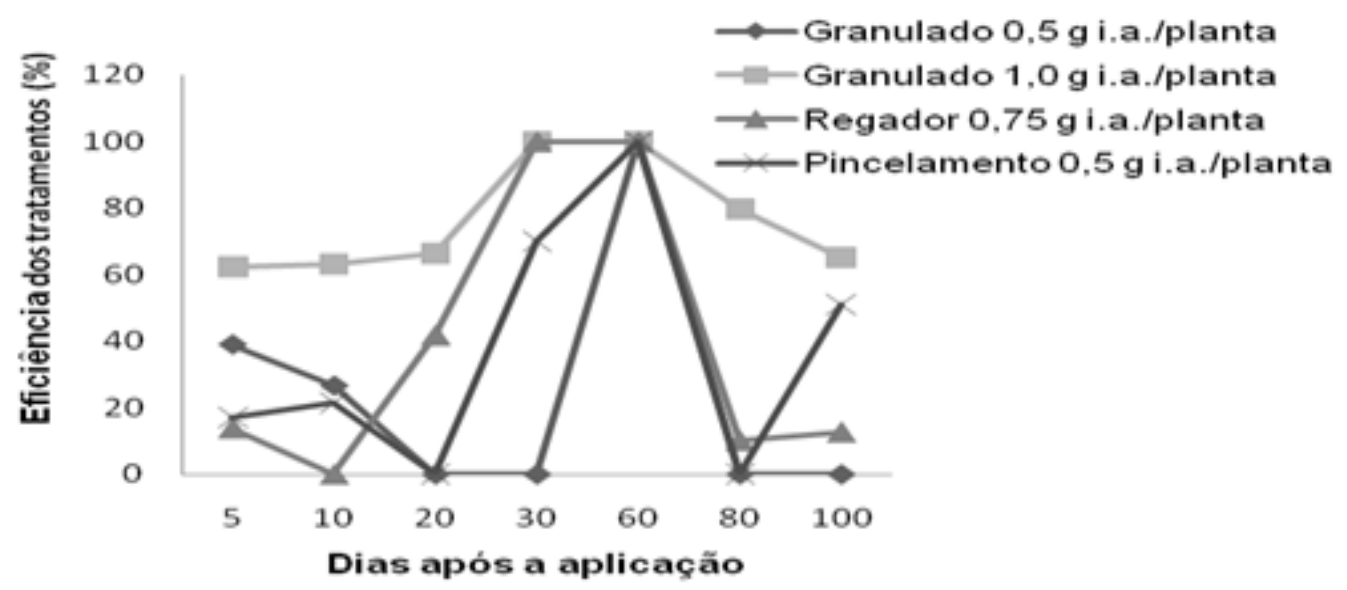

Figura 5. Porcentagem de eficiência dos melhores tratamentos após a aplicação do produto tiametoxan para controle de ninfas do percevejo-de-renda. Itiquira - MT, novembro de 2003.

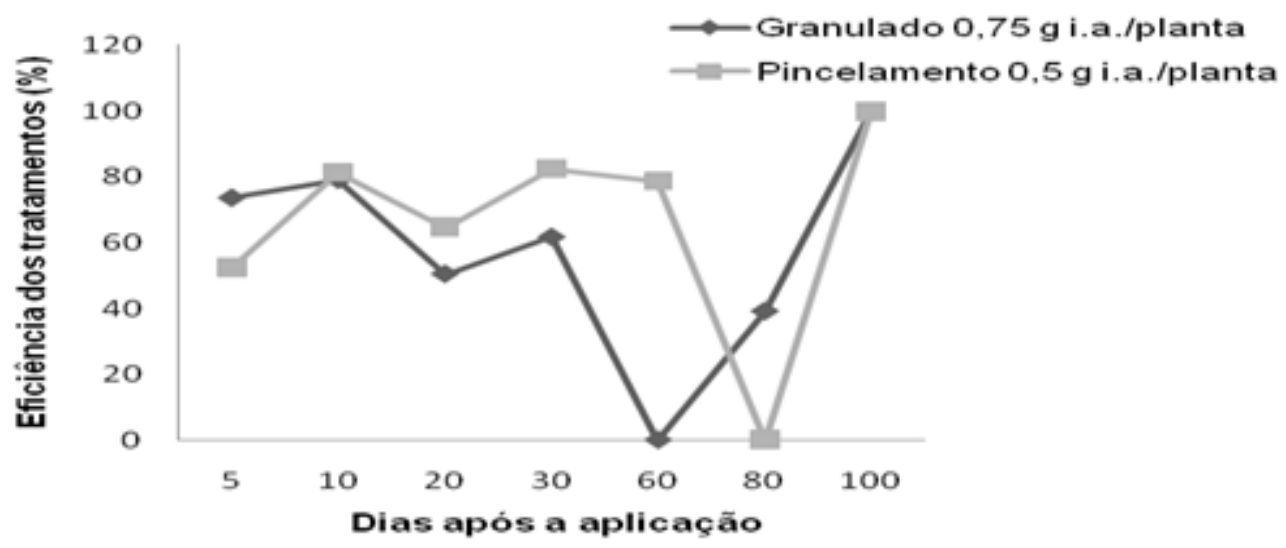

Figura 6. Porcentagem de eficiência dos melhores tratamentos após a aplicação do produto tiametoxan para controle de adultos do percevejo-de-renda. Itiquira - MT, novembro de 2003.

\section{CONCLUSÃO}

Pode-se inferir que dentre os tratamentos escolhidos para este estudo, o modo de aplicação granulado no solo e o pincelamento são os tratamentos mais indicados para o controle de L. heveae por apresentar eficiência tanto para o adulto como para a ninfa. Entretanto, cabe ressaltar, a importância de realizar novas pesquisas sobre os modos de aplicação que apresentaram superioridade de controle do percevejo-de-renda neste estudo, de modo a recomendá-los com maior precisão.

\section{REFERÊNCIAS BIBLIOGRÁFICAS}

BATISTA FILHO, A.; LEITE, L. G.; LAMAS, C.; MARTINS, A. L. M.; SILVEIRA, L. C. P.; ALVES, L. F. A.1998. Flutuação populacional do percevejo-de-renda Leptopharsa heveae em Pindorama, SP. Arquivo do Instituto Biológico, Campinas, SP, v. 65, p. 44.

BATISTA FILHO, A.; LEITE, L. G.; SILVEIRA, A. P. 1995. Ocorrência do percevejo-de-renda,
Leptopharsa 
heveae, em Buritama, SP, Arquivo do Instituto Biológico, Campinas, SP, v. 62 , p. 81.

BERNARDES, M. S. 1992. Cultura da seringueira no Estado de São Paulo e perspectivas para produção de mudas. In: MEDRADO, M. J. S.; BERNARDES, M. S.; COSTA, J. D.; MARTINS, A. N. (Eds.). Formação de mudas e plantio da seringueira. Piracicaba: ESALQ, 158 p.

CARPENTER, T. G.; REICHARD, D. L.; KHAN, A. S. 1983. Spray deposition from a row-crop airblast sprayer. Transactions of Asae, v. 26, n. 2, p. 338-342.

DEVLIN, D. L.; LONG, J. H.; MADDUX, L. D. 1991. Using reduced rates of postemergence herbicides in soybeans (Glycine max). Weed Technology, v. 5, p. 834-840.

HENDERSON, C.F., TILTON, E.W. 1955. Tests with acaricides against the brown wheat mite. Journal of Economic Entomology. Baltimore, v. 48, n. 2, p. 157-161.

JUNQUEIRA, N. T. V. 1994. Névoa protetora. Globo Rural, São Paulo, v. 3, p. 43-46.

JUNQUEIRA， N. T. V.; PINHEIRO, E.; ALVES, R. T.; CELESTINO FILHO, P.; PEREIRA, A. V.; OLIVEIRA, M. A.; FIALHO, J. F.; GASPAROTTO, L. 1999. Controle biológico do percevejo-de-renda (Leptopharsa heveae Drake \& Poor) em seringais de cultivo. Planaltina: EMBRAPA CERRADOS, 30 p. (Circular Técnica, 3).

MATTHEWS, G. A. 2000. Pesticide application methods. London: Black Well Science. 432p.

PINO, F. A.; SANTOS, V. L. F.; MARTIN, N. B.; CORTEZ, J. V. (2000). Perfil da heveicultura no estado de São Paulo. Informações Econômicas, São Paulo, SP, v. 30, n. 8, p. 7-40.

SCOMPARIM, C. H. J. 1997. Crisopídeos (Neuroptera: Chrysopidae) em seringueira (Hevea brasiliensis Muel Arg.) e o seu potencial no controle biológico do percevejo-de-renda (Leptopharsa heveae Drake \& Poor) (Hemíptera: Tingidae). 1997. $147 \mathrm{f}$. Dissertação (Mestrado em Entomologia) - Faculdade de Ciências Agrárias e Veterinárias, Universidade Estadual Paulista, Jaboticabal.

TANZINI, R. M.; LARA, F. M. 1998. Biologia do percevejo-de-renda-daseringueira Leptopharsa hevea Drake \& Poor (Heteroptera: Tingidae). Ecossistema, Espírito Santo do Pinhal, v. 23, p. 65-67.

VAL, A. J. 1994. Névoa protetora: Os fungos pulverizados nos seringais controlam a mosca da renda, uma praga nos cultivos do Mato Grosso. Revista Globo Rural, Rio de Janeiro, RJ, p. 4346.

VENDRAMIM, J. D. 1992. Pragas de viveiros e jardins clonais de seringueira e seu controle. In: MEDRADO, M. J. S.; BERNARDES, M. S.; COSTA, J. D.; MARTINS, A. N. (Eds.). Formação de mudas e plantio da seringueira. Piracicaba: ESALQ, 158 p.

WILES, T. 1996. Projeto e uso de equipamentos de pulverização agrícola na América Latina. (Parte II Brasil). In: SINTAG 96 - SIMPÓSIO INTERNACIONAL DE TECNOLOGIA DE APLICAÇÃO DE PRODUTOS FITOSSANITÁRIOS, 1., 1996, Águas de Lindóia. Anais... Águas de Lindóia, 1996. p. 16-29. 